\title{
The Revised Sunspot Record in Comparison to Cosmogenic Radionuclide-Based Solar Activity Reconstructions
}

\author{
Raimund Muscheler ${ }^{1}(\mathbb{D}) \cdot$ Florian Adolphi $^{1}$. \\ Konstantin Herbst ${ }^{1}$ • Andreas Nilsson ${ }^{1}$
}

Received: 10 February 2016 / Accepted: 5 August 2016 / Published online: 27 September 2016

(c) The Author(s) 2016. This article is published with open access at Springerlink.com

\begin{abstract}
Recent revisions in the sunspot records illustrate the challenges related to obtaining a 400-year-long observational record of past solar-activity changes. Cosmogenic radionuclides offer the possibility of obtaining an alternative and completely independent record of solar variability. Here, we illustrate that these records offer great potential for quantitative solar-activity reconstructions far back into the past, and we provide updated radionuclide-based solar-activity reconstructions for the past 2000 years. However, cosmogenic-radionuclide records are also influenced by processes independent of solar activity, leading to the need for critical assessment and correction for the non-solar influences. Independent of these uncertainties, we show a very good agreement between the revised sunspot records and the ${ }^{10} \mathrm{Be}$ records from Antarctica and, in particular, the ${ }^{14} \mathrm{C}$-based solar-activity reconstructions. This comparison offers the potential of identifying remaining non-solar processes in the radionuclide-based solar-activity reconstructions, but it also helps identifying remaining biases in the recently revised sunspot records.
\end{abstract}

Keywords Cosmogenic radionuclides $\cdot$ Sunspots $\cdot$ Solar-activity reconstruction $\cdot$ Solar modulation $\cdot{ }^{14} \mathrm{C} \cdot{ }^{10} \mathrm{Be}$

\section{Introduction}

Documentations of the occurrence and number of sunspots are the basis for the longest record of direct solar observations, but reliable data do not extend much further than 400 years into the past (Hoyt and Schatten, 1998). Therefore, we need to consider indirect so-called "proxy data" to extend our information about past solar variability back in time and to test the suggested revisions in the sunspot-number reconstructions. The most

Sunspot Number Recalibration

Guest Editors: F. Clette, E.W. Cliver, L. Lefèvre, J.M. Vaquero, and L. Svalgaard

R. Muscheler

Raimund.muscheler@geol.lu.se

1 Department of Geology, Quaternary Sciences, Lund University, Sölvegatan 12, 22362 Lund, Sweden 
reliable indirect solar-proxy data come from cosmogenic radionuclides such as ${ }^{10} \mathrm{Be},{ }^{14} \mathrm{C}$, and ${ }^{36} \mathrm{Cl}$ (e.g. Beer et al., 1990; Lal and Peters, 1967). These particles are produced during the interaction of galactic and solar cosmic rays with constituents of the Earth's atmosphere (Lal and Peters, 1967). Because of their sporadic nature and their on-average relatively low energies, solar-particle events are assumed to contribute negligibly to the long-term average production rate of cosmogenic radionuclides. Galactic cosmic rays, on the other hand, are considered to be mainly responsible for the production of radionuclides in the Earth's atmosphere. The varying solar magnetic shielding modulates the flux of galactic cosmic rays within the heliosphere (Lal and Peters, 1967). Therefore, cosmogenic radionuclide records can provide information about the open solar magnetic field in the past. However, cosmogenic radionuclide records not only depend on solar shielding, but also on other factors such as i) influences of the geomagnetic shielding effect, ii) transport effects in the atmosphere (e.g. in the case of ${ }^{10} \mathrm{Be}$ ), and iii) deposition effects and/or carbon-cycle effects (in the case of ${ }^{14} \mathrm{C}$ ) (Lal and Peters, 1967).

Despite these complications, quantitative reconstruction of solar modulation, sunspot numbers, and solar irradiance have been attempted based on cosmogenic-radionuclide data (e.g. Bard et al., 2000; Muscheler et al., 2007; Solanki et al., 2004; Steinhilber et al., 2012). Such reconstructions have provided information on, for example, the existence of the solar 11-year cycle during the Maunder minimum (Beer et al., 1990) or on longer-term cycles such as the 88-year or the 207-year solar cycles (e.g. Damon and Sonett, 1991). These reconstructions form the basis for assessing past temporal variations in solar irradiance that are used for paleoclimate model runs (e.g. Schmidt et al., 2012), and they have provided numerous examples of the coupling between past changes in solar activity and climate (e.g. Bond et al., 2001; Adolphi et al., 2014). However, there is still a debate about past solar-activity levels that is mainly based on differences in the data underlying these reconstructions. For example, Usoskin et al. (2003) favored the ${ }^{10}$ Be record from Southern Greenland, which appears to be in good agreement with previous sunspot reconstructions. In contrast, Bard et al. (2000) and Muscheler et al. (2007) came to different conclusions about past solar activity based on ${ }^{10} \mathrm{Be}$ data from the South Pole and ${ }^{14} \mathrm{C}$ data in combination with neutron-monitor data.

In the following we review the available ${ }^{10} \mathrm{Be}$ and ${ }^{14} \mathrm{C}$ data and discuss the agreement and disagreement between the records. We show that the various ice core ${ }^{10} \mathrm{Be}$ records generally agree well and that there are relatively small differences that have led to the different assessments of past solar activity with respect to the recent decades. We update the solarmodulation reconstructions with the latest knowledge about the local interstellar cosmic-ray spectrum (LIS) and the related ${ }^{10} \mathrm{Be}$ and ${ }^{14} \mathrm{C}$ production rates depending on solar and geomagnetic shielding. Finally, the updated records are compared to the revised sunspot records as published recently by Clette et al. (2014) (sunspot number) and Svalgaard and Schatten (2016) (group sunspot number).

\section{Background}

\subsection{Production Models}

The main source for the production of cosmogenic radionuclides in the Earth's atmosphere are galactic cosmic rays (GCRs). As soon as these charged particles encounter the heliospheric magnetic field (HMF), the low-energy particles are deflected, resulting in a modulation of the low-energy spectrum that strongly depends on solar activity. Thus, much higher 
particle intensities can be detected inside the heliosphere during solar-minimum conditions compared to phases of high solar activity. The so-called local interstellar spectrum (LIS), i.e. the particle spectrum outside the heliosphere, is of major importance for the numerical reconstruction of the production rate values (see, e.g., Herbst et al., 2010). Unfortunately, until very recently, the LIS has not been measured in situ; thus, multiple LIS models exist in the literature (e.g. Burger, Potgier, and Heber, 2000; Garcia-Munoz, Mason, and Simpson, 1975; Webber and Higbie, 2010). However, with Voyager 1 crossing the outer boundary of our solar system in 2012, the LIS of galactic protons below $\approx 500 \mathrm{MeV}$ have been measured for the first time (Stone et al., 2013). On the basis of these measurements, Potgieter et al. (2014) developed a new proton LIS model (denoted as PG14), also taking into account the spacecraft-borne Payload for Antimatter Matter Exploration and Light-nuclei Astrophysics (PAMELA) measurements above $\approx 1 \mathrm{GeV}$.

The transport of GCRs within the heliosphere can be described by the Parker equation (Parker, 1965) giving the phase-space distribution as a function of the main modulation processes such as convection, drifts, diffusion, and adiabatic energy changes. A widely used, but only first-order approximation, is the so-called force-field approach (e.g. Gleeson and Axford, 1968; Moraal, 2013), which is a simple convection-diffusion equation neglecting, e.g., drifts as well as adiabatic energy-loss processes. Here, the transport only depends on one free parameter, the solar modulation function [ $\Phi]$ given by $\Phi=(Z e / A) \phi$, with $Z$ and $A$ as charge and mass number of cosmic-ray nuclei. $\phi$ represents the solar-modulation parameter, which is directly linked to solar activity. The time-dependent differential GCR flux at $1 \mathrm{AU}$ is given by

$$
J_{1 \mathrm{AU}}(E, \Phi)=J_{\mathrm{LIS}}(E+\Phi)+\frac{(E)\left(E+2 E_{\mathrm{r}}\right)}{(E+\Phi)\left(E+\Phi+2 E_{\mathrm{r}}\right)},
$$

where $J_{\text {LIS }}$ is the differential LIS spectrum, $E$ the kinetic energy of the primary GCR particle, and $E_{\mathrm{r}}$ the rest energy of the GCR (for protons $E_{\mathrm{r}} \approx 938 \mathrm{MeV}$ ).

In addition to the HMF, once the particles arrive at Earth's vicinity, they also encounter the geomagnetic field, which shields the atmosphere from low-energy primaries. However, the particles that are able to enter the Earth's atmosphere interact with the atmospheric constituents. When the energy of the GCR particle is high enough, these interactions lead to the development of altitude-dependent secondary-particle cascades mainly consisting of hadronic particles (e.g. Simpson, 2000). Very important for the production of both short- and long-lived cosmogenic radionuclides are the secondary neutrons and protons so produced.

Numerically, the production rate $[P]$ of a cosmogenic radionuclide of type $j$ can be described in the following way (see, e.g., Masarik and Beer, 1999):

$$
P_{j}\left(\phi, R_{C}, x\right)=\sum_{i} N_{i} \sum_{k} \int_{E_{C}}^{\infty} \sigma_{i j k}\left(E_{k}\right) J_{k}\left(\phi, E_{k}, x\right) \mathrm{d} E_{k} .
$$

The production rate is a function of the density of target atoms $[N]$ of species $i$, the production cross-sections $[\sigma]$, and the secondary particle flux $\left[J_{k}\right]$, which depends strongly on atmospheric depth $[x]$ and on solar shielding $[\phi]$ and geomagnetic shielding $\left[R_{C}\right] . R_{C}$ is related to the energy $E_{C}$ a particle must have in order to be able to enter the atmosphere depending on the geomagnetic shielding at a certain location. The integration of $P_{j}$ over atmospheric depth $[x]$ and the geographic locations gives the global production rates. In this study we investigate the global ${ }^{10} \mathrm{Be}$ and ${ }^{14} \mathrm{C}$ production rates based on the computations by Masarik and Beer (1999) and those by Kovaltsov and Usoskin (2010) and Kovaltsov, Mishev, and Usoskin (2012). 
Figure 1 Solar-modulation reconstructions based on neutron-monitor data (Masarik and Beer, 1999) extended with ionization-chamber data and balloon-borne measurements of cosmic rays (McCracken and Beer, 2007) (black line). An alternative reconstruction by Usoskin, Bazilevskaya, and Kovaltsov (2011) is shown as a dotted-gray line. Both records are transferred to the LIS model of Potgieter et al. (2014).

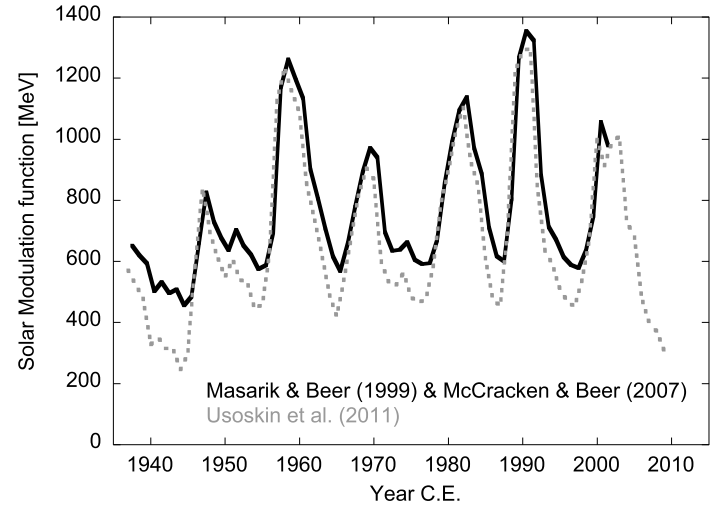

\subsection{Neutron-Monitor Data}

To reconstruct solar activity over the past 2000 years, a calibration with the constantly measured cosmic-ray flux record during present conditions is required. As shown by McCracken and Beer (2007), measurements of balloon-borne ionization chambers and neutron monitors (NMs), going back to the 1930 s, can be used to intercalibrate with the existing ${ }^{10} \mathrm{Be}$ and ${ }^{14} \mathrm{C}$ records on the basis of computed yield functions (see, e.g., McCracken and Beer, 2007, for further information). However, these inter-calibrations strongly depend on the applied LIS and the numerical computations. In this study we use the $\Phi$-reconstructions by McCracken and Beer (2007), which are based on the computations by Masarik and Beer (1999) and those by Usoskin, Bazilevskaya, and Kovaltsov (2011) to reconstruct solar activity for the past 2000 years.

As described by, e.g., Herbst et al. (2010), solar-modulation parameter values based on one LIS can be transformed into values of another LIS through linear regression. Based on their method, we transformed the $\Phi$-values used by McCracken and Beer (2007) (LIS model by Garcia-Munoz, Mason, and Simpson, 1975) and Usoskin, Bazilevskaya, and Kovaltsov (2011) (LIS model by Usoskin et al., 2005 on the basis of Burger, Potgier, and Heber, 2000) to values based on the newest LIS model by Potgieter et al. (2014), upon which all of the subsequent results are based. The following regression functions were used:

$$
\phi_{\mathrm{PG} 14}=\left\{\begin{array}{l}
0.995 \phi_{\mathrm{GM} 75}+77.39 \mathrm{MV} \\
1.029 \phi_{\mathrm{US} 05}+28.00 \mathrm{MV}
\end{array}\right.
$$

Figure 1 shows the solar-modulation function based on NM data (Masarik and Beer, 1999) extended with ionization-chamber data and balloon-borne measurements of cosmic rays (McCracken and Beer, 2007). In addition, we show the alternative reconstruction by Usoskin, Bazilevskaya, and Kovaltsov (2011). As both were transferred to the LIS by Potgieter et al. (2014), the differences are most likely due to different yield functions (i.e. the number of secondary particles produced per incident cosmic-ray particle at a certain NM site) and/or differences in neutron-monitor data included in the calculation. As we show in the following, these different records lead to a different normalization of the ${ }^{14} \mathrm{C}$-based solar-modulation records, but do not strongly affect the inferred relative changes in solar modulation. 
Figure 2 Normalized ice-core ${ }^{10}$ Be concentrations from Antarctica and Greenland. The black and gray lines indicate the normalized ${ }^{10} \mathrm{Be}$ concentration. Dotted lines bridge data gaps in each record. The red lines depict ten-year averages of each dataset. Data are shown for (from top to bottom) Siple Dome (Nishiizumi and Finkel, 2007), South Pole (Raisbeck et al., 1990), Dome Fuji (Horiuchi et al., 2008), Dome C (Beer, Raisbeck, and Yiou, 1991; Raisbeck et al., 1981), Milcent (Beer, Raisbeck, and Yiou, 1991), Dye-3 (Beer et al., 1990), Camp Century (Beer et al., 1988), GRIP (Muscheler et al., 2004; Yiou et al., 1997), and NGRIP (Berggren et al., 2009). The bottom panel indicates the temporal coverage of each record.

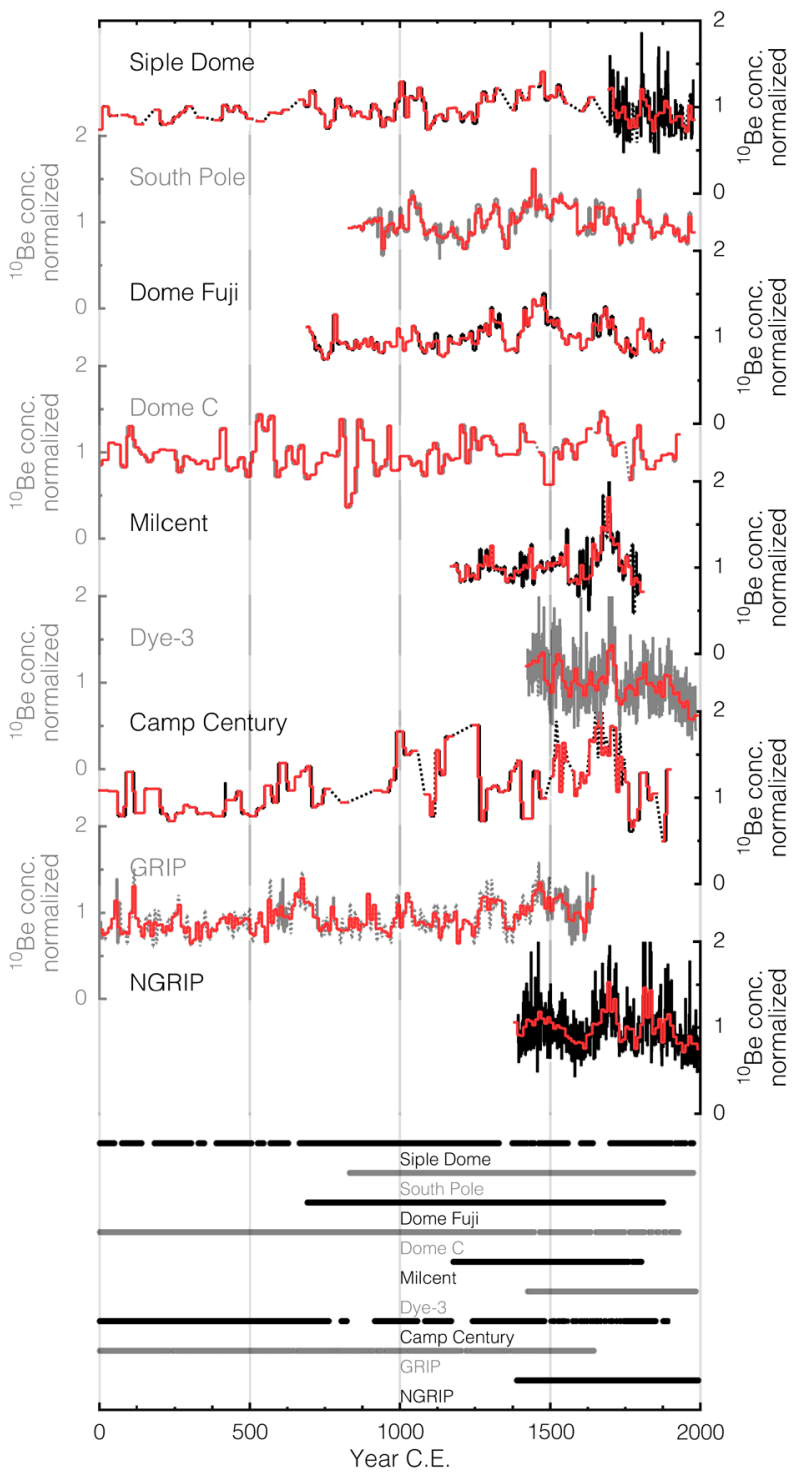

\section{3. ${ }^{10}$ Be Data}

Figure 2 shows ice core ${ }^{10} \mathrm{Be}$ records from Greenland and Antarctica that are used in this study. Of the publicly available records, we limited our choice to those that are longer than 500 years and provide a temporal resolution on the order of 20 years or less. This includes four Antarctic ice cores: Siple Dome (Nishiizumi and Finkel, 2007), South Pole (Raisbeck et al., 1990), Dome Fuji (Horiuchi et al., 2008), and Dome C (Beer, Raisbeck, and Yiou, 1991; Raisbeck et al., 1981). From Greenland, five ice cores fulfill our criteria: Milcent (Beer, Raisbeck, and Yiou, 1991), Dye-3 (Beer et al., 1990), Camp Century (Beer et al., 1988), GRIP (Muscheler et al., 2004; Yiou et al., 1997) and NGRIP (Berggren et al., 2009). 
Figure 3 Correlation

coefficients (color scale) between the different ${ }^{10} \mathrm{Be}$ records shown in Figure 2. In addition, the correlation of each ${ }^{10} \mathrm{Be}$ record to the mean of all other records is indicated ("Mean"). Significant correlations are indicated by open $(95 \%)$ and filled (99\%) circles.

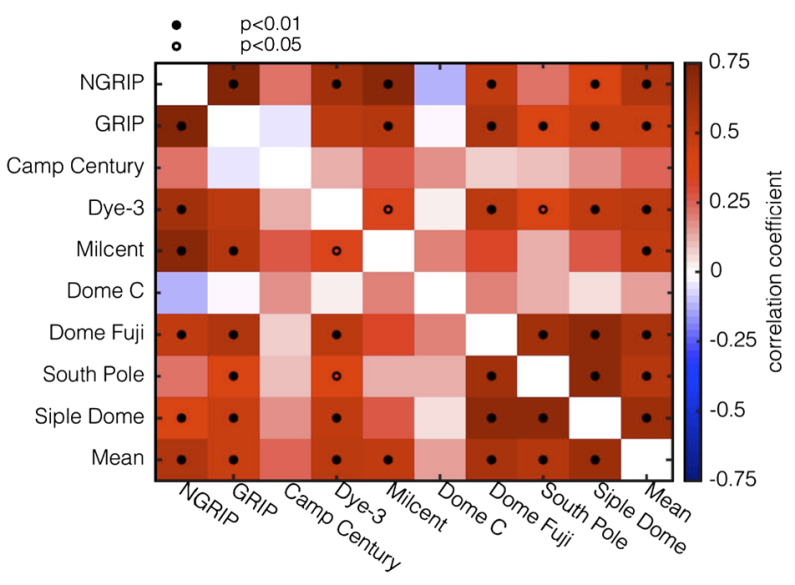

As mentioned in the introduction, variations in ice-core ${ }^{10} \mathrm{Be}$ concentrations do not only reflect fluctuations in the ${ }^{10} \mathrm{Be}$ production rates, but may also be influenced by changes in atmospheric circulation, aerosol transport, and deposition (Adolphi and Muscheler, 2016; Field et al., 2006; Heikkilä et al., 2011; Pedro et al., 2011, 2012, 2006). For example, it has been suggested that volcanic aerosols influence the scavenging of ${ }^{10} \mathrm{Be}$, i.e. leading to enhanced ${ }^{10} \mathrm{Be}$ deposition following such events (Baroni et al., 2011). However, our knowledge about such effects and their influences on ${ }^{10} \mathrm{Be}$ records is limited. Therefore, attempts to correct for the above-mentioned non-production effects on ${ }^{10} \mathrm{Be}$ still contain significant uncertainties. In addition, data-quality issues might affect some of the records. This becomes apparent when correlating the records to each other, as shown in Figure 3. While most correlations are indeed significant, there are also a number of insignificant correlations between single records. Most notably, the ${ }^{10} \mathrm{Be}$ records from Dome $\mathrm{C}$ and Camp Century are not significantly correlated with any other record. Since the low correlations between single icecore records may in part be caused by a limited temporal overlap, we additionally tested the correlation of each record with the average of all other ice cores (Figure 3, "mean"). In doing so, we found that all ice-core records except those from Dome $\mathrm{C}$ and Camp Century share a significant amount of covariability that most likely reflects the common production-rate signal. The averaged records are subsequently referred to as "stacks".

Influences of atmospheric circulation and precipitation rate on ${ }^{10} \mathrm{Be}$ can be expected to differ between Greenland and Antarctica because of their large geographical separation. It is a priori unknown whether one region can be assumed to be more or less susceptible to these influences than the other. Hence, we separately produced ${ }^{10} \mathrm{Be}$ stacks from ice-core records from these two regions. To account for differences in the mean ${ }^{10} \mathrm{Be}$ deposition rates at different sites, we normalized all Greenland ${ }^{10} \mathrm{Be}$ records to the Dye-3 ${ }^{10} \mathrm{Be}$ data for their overlapping periods. Similarly, we normalized all Antarctic records to the South Pole ${ }^{10} \mathrm{Be}$ data. Normalizing to other records has only a minor influence on the resulting stacked record. Subsequently, we created 1000 stacked ${ }^{10}$ Be records for the two regions through bootstrapping, i.e. we randomly sampled from the available ${ }^{10} \mathrm{Be}$ records at each point in time and calculated the mean. Consequently, by taking the mean and standard deviation of all 1000 realizations, we obtained a Greenland and Antarctic ${ }^{10} \mathrm{Be}$ stack including confidence intervals (see Figure 4). It should be noted that these confidence intervals solely reflect the spread of the individual data series (and hence, they are zero when only one record covers a certain time period) and not true uncertainties, as all records from one region may be biased 
Figure 4 Stacked normalized decadal ${ }^{10} \mathrm{Be}$ variations from Greenland (orange) and Antarctica (blue). Both records are shown together with their $\pm 1 \sigma$ uncertainty (shading) based on bootstrapping (see text).

a: Greenland and Antarctic ${ }^{10} \mathrm{Be}$ stacks of all available ${ }^{10} \mathrm{Be}$ records shown in Figure 2, the correlation coefficient and its $p$-value. b: Differences

(Greenland-Antarctica) between the curves shown in panel a.

c: Similar to panel a, but excluding the data from Camp Century and Dome $\mathrm{C}$ from the Greenland and Antarctic ${ }^{10} \mathrm{Be}$ stack, respectively. d: Differences between the curves shown in panel c.

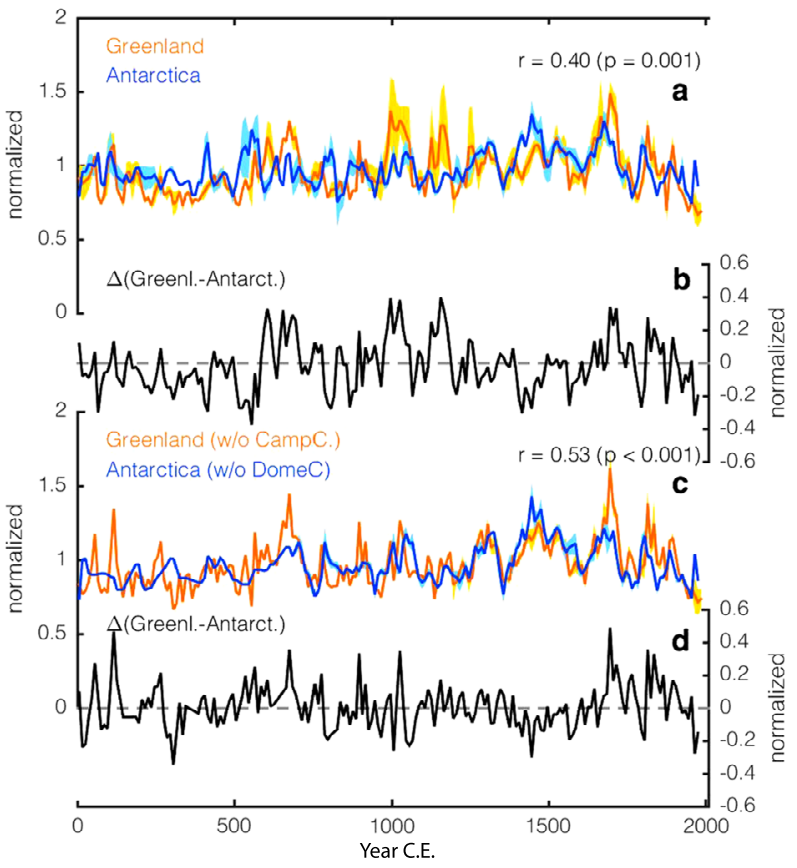

in a similar way. Since the Camp Century and Dome $\mathrm{C}$ records do not correlate significantly with any other ${ }^{10} \mathrm{Be}$ record (Figure 3 ), we calculated the ${ }^{10} \mathrm{Be}$ stacks using all available records (Figure 4a), and without Camp Century and Dome C (Figure 4c). Excluding Camp Century and Dome $\mathrm{C}$ leads to an improved agreement between the regional ${ }^{10} \mathrm{Be}$ stacks (the correlation coefficient increases from 0.4 to 0.53 ). The differences between the two stacks are reduced especially around $1000-1200$ C.E. and 1400-1500 C.E. when the data from Camp Century and Dome $\mathrm{C}$ are omitted (Figure $4 \mathrm{~b}$ and $4 \mathrm{~d}$ ). However, systematic differences between the ${ }^{10} \mathrm{Be}$ stacks from both regions remain, especially from about 1600 C.E. onward. The relatively small and short-term disagreement between Antarctic and Greenland stacks for about the last 50 years is noteworthy in this context. This difference can have a major impact on the conclusions about past solar activity when relating recent solar activity to activity in the past millennium.

\section{4. ${ }^{14} \mathrm{C}$ Data and Production Rate}

Figure 5 depicts the atmospheric ${ }^{14} \mathrm{C}$ concentration changes as inferred from tree-ring ${ }^{14} \mathrm{C}$ measurements compiled in the most recent IntCal13 ${ }^{14} \mathrm{C}$ calibration record for the northern (Reimer et al., 2013) and southern (Hogg et al., 2013) hemisphere complemented by annual northern-hemisphere data for the past about 500 years (Stuiver, Reimer, and Braziunas, 1998). Data after 1950 C.E. are not shown, as atmospheric ${ }^{14} \mathrm{C}$ is heavily influenced by the anthropogenic ${ }^{14} \mathrm{C}$ produced during the nuclear bomb tests and therefore cannot be used to reconstruct solar activity. As we are interested in the globally averaged ${ }^{14} \mathrm{C}$ production rate, we used an average northern and southern hemisphere ${ }^{14} \mathrm{C}$ record to infer solar activity. We still retained the high-resolution annual ${ }^{14} \mathrm{C}$ data for the most recent period, but we corrected the absolute level for the offset induced by the time-dependent northern and southern hemisphere difference. 
Figure 5 The $\Delta^{14} \mathrm{C}$ data used in this study. The black dots show the northern-hemisphere ${ }^{14} \mathrm{C}$ data (Reimer et al., 2013; Stuiver, Reimer, and Braziunas, 1998), while the gray data represent the southern-hemisphere $\Delta^{14} \mathrm{C}$ data (Hogg et al., 2013).

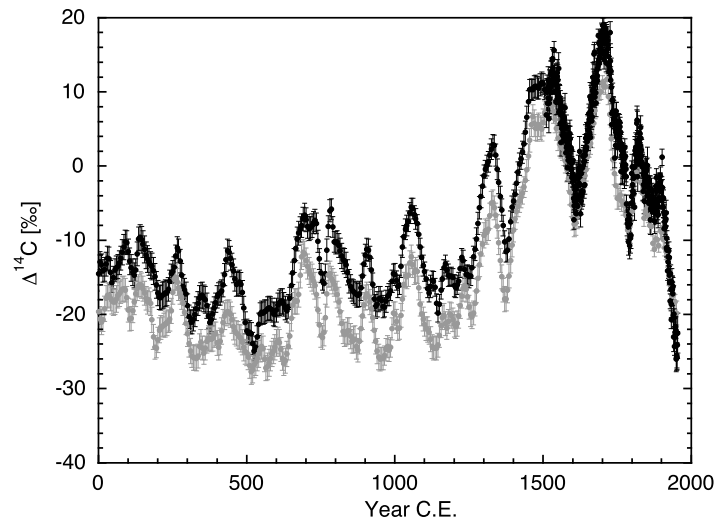

Figure 6 Comparison of the ${ }^{14} \mathrm{C}$ production rate inferred in this study (black with gray error bar) to the result by Roth and Joos (2013) (red-dotted line).

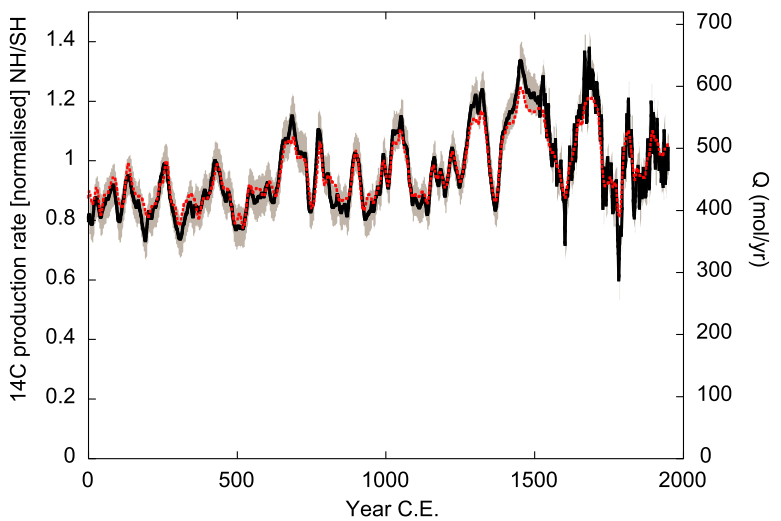

With a Monte Carlo approach and by using a box-diffusion carbon-cycle model (Muscheler et al., 2007), we calculated 1000 versions of the ${ }^{14} \mathrm{C}$ production rate consistent with the atmospheric ${ }^{14} \mathrm{C}$ data within its errors. The effect of fossil-fuel burning on ${ }^{14} \mathrm{C}$ (diluting ${ }^{14} \mathrm{C}$ in relation to ${ }^{12} \mathrm{C}$ ) was accounted for by including the estimated $\mathrm{CO}_{2}$ emissions from fossil-fuel burning (Muscheler et al., 2007). This method correctly reproduces the atmospheric $\mathrm{CO}_{2}$ changes from 1850 to 1950 C.E., thereby supporting the estimates of the fossil-fuel-burning influence on $\Delta^{14} \mathrm{C}$. To eliminate large short-term scatter, which would lead to unphysical large ${ }^{14} \mathrm{C}$ variations, we smoothed each of the $\Delta^{14} \mathrm{C}$ records generated in the Monte Carlo process using a Gaussian smoothing filter ( $\sigma=2$ years).

Our results generally agree well with independent calculations based on the more sophisticated carbon-cycle model of Roth and Joos (2013) (Figure 6). An upward trend in the results of Roth and Joos (2013) from 1930 to 1950 C.E. is unexpected and might be caused by the relatively slow $\Delta^{14} \mathrm{C}$ decline in the southern hemisphere and, therefore, might overestimate the ${ }^{14} \mathrm{C}$ production rate during this period. This feature is less strongly expressed in the results from our calculation. One possible reason is that we used the higher-resolution annual $\Delta^{14} \mathrm{C}$ data during this period, while Roth and Joos (2013) applied the smoothed Int$\mathrm{Cal}{ }^{14} \mathrm{C}$ record. Furthermore, Roth and Joos (2013) indicated slightly smaller amplitudes of the typical solar-induced centennial-scale ${ }^{14} \mathrm{C}$ production rate variations. This is probably caused by a slower ${ }^{14} \mathrm{C}$ uptake of the oceans in the carbon-cycle model of Roth and Joos 
(2013). Nevertheless, in general the different ${ }^{14} \mathrm{C}$ production rate results agree well within our inferred uncertainty estimates (gray band in Figure 6).

\subsection{Geomagnetic Field Data}

For solar-activity reconstructions based on cosmogenic-radionuclide records, we need to correct for the geomagnetic-field influence as the atmospheric production rate of cosmogenic radionuclides is inversely related to the strength of the geomagnetic-field intensity. As the cosmic-ray modulation is most important far away from the Earth's surface, where the higher moments of the geomagnetic field do not significantly contribute to the shielding, the production rate is predominantly influenced by the geomagnetic dipole moment. Internally driven geomagnetic-field changes are usually associated with changes in the production rate on millennial timescales, 2000-3000 years and longer (Snowball and Muscheler, 2007; Wagner et al., 2000), but they probably already start to play a significant role on timescales of 500 years (Korte and Muscheler, 2012).

To determine the dipole moment, it is necessary to filter out regional differences in geomagnetic-field intensities, which requires data with good global coverage. This has traditionally been done by averaging, or in some other way combining, all available archaeointensity data (including data from igneous rocks) assuming that all non-dipole field contributions will be minimized in the process (e.g. Knudsen et al., 2008 shown in Figure 7). However, the effectiveness of this approach has been questioned because of the strong geographical bias in the data distribution, with the majority of the measurements concentrated on Europe and the northern hemisphere (e.g. Korte and Constable, 2005; Nilsson, Muscheler, and Snowball, 2011). Efforts to construct global geomagnetic-field models have, to a certain extent, overcome this problem by including directional data as well as intensities and allowing for more complex field structures; see A_FM (Licht et al., 2013) shown in Figure 7. To reduce the geographical bias in the data distribution, sedimentary palaeomagnetic data are sometimes also included, which provide a vastly improved data coverage but lead to models with lower temporal resolution; see pfm9k.1b (Nilsson et al., 2014) in Figure 7. The low temporal resolution is due to the generally large chronological uncertainties of sedimentary palaeomagnetic data and potential smoothing associated with the gradual processes by which the magnetization is acquired over time in the sediments (Roberts and Winklhofer, 2004).

Despite recent advances in geomagnetic-field modeling, reconstructing past changes in the dipole moment beyond historical observations is still proving to be a challenge (Panovska et al., 2015). Figure 7 shows that the different geomagnetic-field reconstructions largely agree in their broad trend, i.e. all records show a similar long-term trend gradually decreasing toward the present. In addition, the most recent dipole estimates agree mostly within their respective error estimates. Nevertheless, for solar-activity reconstruction it also implies that there are still unresolved (possibly systematic) differences in the geomagneticfield reconstructions that directly translate into uncertainties in the estimates of solar modulation.

To provide the best possible continuous dipole-moment reconstruction for the past 2000 years, we spliced together the dipole-moment estimates from two recent archaeo/ palaeomagnetic field models, A_FM (Licht et al., 2013) and pfm9k.1b (Nilsson et al., 2014) based on 1000 and 2000 bootstrap models, respectively, with predictions of models based on historical field observations: gufm1 (Jackson, Jonkers, and Walker, 2000) between 1840 1990 C.E. and IGRF 12 th generation (Thebault et al., 2015) up to 2000 C.E. To avoid discontinuities in the transition, each individual bootstrap model was joined together with the historical field estimate by spline interpolation over a 100-year period (1740-1840 C.E.); see Figure 7. 


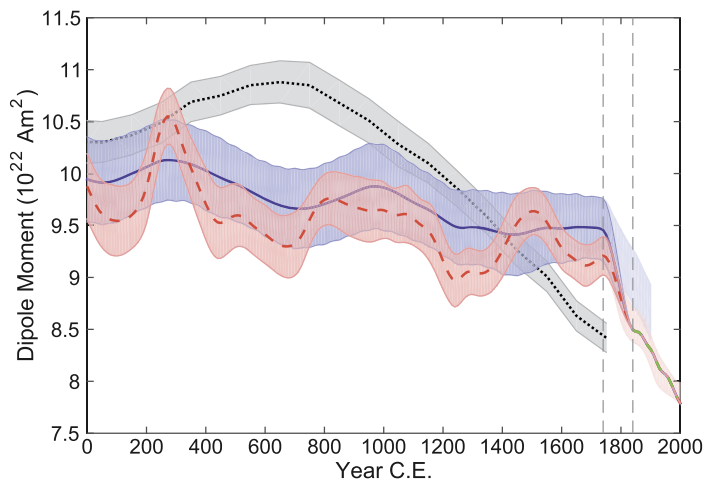

Figure 7 Different reconstructions of the geomagnetic-field dipole moment over the past 2000 years, all shown with a one- $\sigma$ shaded error envelope. The blue and dashed-red curves show the bootstrap average and standard deviation from the pfm9k.1b (in blue, Nilsson et al., 2014) and the A_FM (dashed-red curve, Licht et al., 2013) geomagnetic-field model. The two models have been joined together with gufm1 and IGRF 12th generation data (Jackson, Jonkers, and Walker, 2000; Thebault et al., 2015, dashed-green curve) over the period $1740-1840$ C.E., highlighted by the vertical-dashed lines. The one- $\sigma$ error envelopes of the original published models are shown for reference in lighter shades of blue and red, respectively, as well as the dipole moment estimates from Knudsen et al. (2008) (dotted-black curve with gray error band).

\subsection{Solar Modulation $[\Phi]$ Reconstruction}

By combining theoretical production-rate models, cosmogenic-radionuclide records, and geomagnetic-field reconstructions, we can infer cosmogenic radionuclide-based solaractivity reconstructions. However, a direct transfer of absolute production-rate estimates to solar-modulation estimates is currently uncertain owing to i) carbon-cycle uncertainties for ${ }^{14} \mathrm{C}$, ii) deposition uncertainties for ${ }^{10} \mathrm{Be}$, and iii) production-rate uncertainties in the computations that are due to the uncertainties in the LIS of cosmic rays and uncertainties in the production cross sections for cosmogenic radionuclides. We note that both LIS and production cross sections are not well known, but they play a crucial role for the numerical computations. Changing to a different LIS model can result in differences of up to $20 \%$, while differences in the cross sections (in particular the neutron cross sections; see, e.g., Caffee et al., 2013) can lead to systematic differences of up to $25 \%$ (Herbst, 2013). Hence, we applied the more reliable approach of connecting (normalizing) the radionuclide variations to the absolute solar-modulation estimates inferred from the neutron-monitor data (Figure 1).

In the case of ${ }^{14} \mathrm{C}$, we normalized the ${ }^{14} \mathrm{C}$ production-rate record to obtain the same average solar-modulation function in the period from 1937 to 1948 (covering one average solar cycle), as indicated by the extended neutron-monitor data. This was done with randomly selected realizations of the Monte Carlo inferred ${ }^{14} \mathrm{C}$ production records and randomly selected geomagnetic-field realization. By repeating this procedure 1000 times and averaging the resulting curves, we could infer an average ${ }^{14} \mathrm{C}$-based solar-modulation function with its corresponding error inferred from the spread of the different results. The ${ }^{10} \mathrm{Be}$ records were normalized in a similar way. However, in this case we took the full period of overlap with the neutron-monitor data to normalize the ${ }^{10} \mathrm{Be}$ record. In this calculation we assumed that the ${ }^{10} \mathrm{Be}$ stacks reflect the globally averaged relative changes in the ${ }^{10} \mathrm{Be}$ production rate. The range of uncertainty based on the geomagnetic-field and ${ }^{10} \mathrm{Be}$ data was included in the same way as for ${ }^{14} \mathrm{C}$. This procedure was carried out for the production-rate models 
and neutron-monitor-based records mentioned above, i.e. Masarik and Beer (1999) combined with McCracken and Beer (2007) and Kovaltsov, Mishev, and Usoskin (2012), Kovaltsov and Usoskin (2010) combined with Usoskin, Bazilevskaya, and Kovaltsov (2011). All solar-modulation functions are reported using the LIS model of Potgieter et al. (2014).

\section{Results}

Figure 8 shows the three independent reconstructions of the solar modulation based on Greenland ${ }^{10} \mathrm{Be}$, Antarctic ${ }^{10} \mathrm{Be}$, and ${ }^{14} \mathrm{C}$. For the Greenland and Antarctic ${ }^{10} \mathrm{Be}$ based reconstructions, we used the ${ }^{10} \mathrm{Be}$ stacks without Camp Century and Dome $\mathrm{C}$, respectively, as shown in Figure 4c. The relatively large ${ }^{10} \mathrm{Be}$ decrease toward today in the Greenland data leads to an inferred strong increase in solar modulation toward today. However, this reconstruction also shows negative (i.e. unphysical) solar-modulation values during the large solar minima of the last millennium, illustrating the challenges of inferring exact amplitudes of past solar-activity variations from this record. The Antarctic ${ }^{10} \mathrm{Be}$ data do not show such a large trend, leading to the conclusion that these records do not indicate exceptionally high solar activity during recent decades (Raisbeck and Yiou, 2004). It can also be seen that Antarctic- and Greenland-based solar-activity reconstructions do not agree during the last 50 years (Figures 4 and 8 ), leading to the conclusion that at least one of the records also contains a non-production signal. As discussed before, this is not unexpected considering the noise that is present in ${ }^{10} \mathrm{Be}$ records (Figure 4). This emphasizes that we need to be careful to avoid overinterpreting the ${ }^{10} \mathrm{Be}$ data, especially when attempting quantitative solar-activity reconstructions. Nevertheless, both ${ }^{10} \mathrm{Be}$ stacks agree with respect to the main features such as, e.g., the three large solar minima from 1300 to 1750 C.E. (Maunder, Spörer, and Wolf minima). Applying the production-rate calculations of Kovaltsov and Usoskin (2010) leads to similar conclusions, although the range of variability in solar modulation is generally slightly smaller.

The ${ }^{14} \mathrm{C}$-based record shares these common large-scale features with the ${ }^{10} \mathrm{Be}$ record. It shows a similar long-term trend throughout most of the past 2000 years, culminating in the

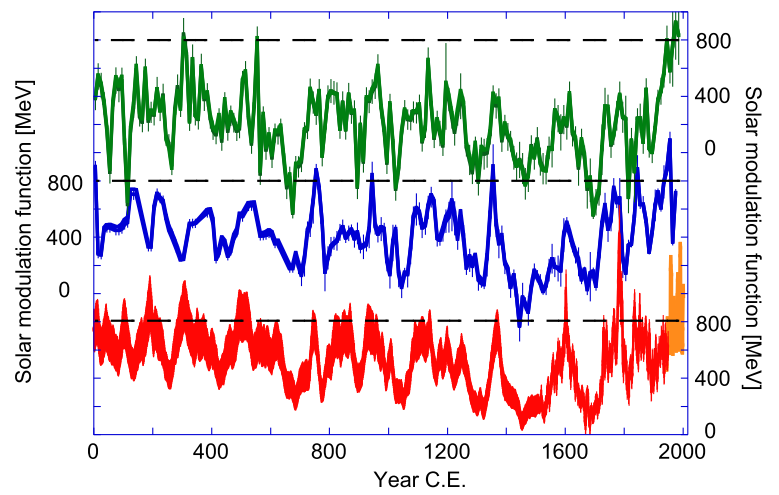

Figure 8 The different $\Phi$-reconstructions based on the Greenland ${ }^{10} \mathrm{Be}$ data (top panel), the Antarctic ${ }^{10} \mathrm{Be}$ data (middle panel), and the ${ }^{14} \mathrm{C}$ data combined with the neutron-monitor-based data (lower panel). The records were calculated with the pfm $9 \mathrm{k} .1 \mathrm{~b}$ geomagnetic-field model results and the production-rate calculation from Masarik and Beer (1999). The horizontal-dashed lines show the average solar modulation inferred from the instrumental data from 1950 to 2000 C.E. 
three deep solar minima mentioned above. These are followed by a general increase in solar activity toward the second part of the twentieth century. In agreement with the Antarcticbased record, solar activity in the second part of the twentieth century is high, but similar levels are reached during several periods in the past 2000 years.

\section{Discussion}

\subsection{Uncertainties in the Solar Modulation Reconstruction}

As shown, there are unresolved differences in the ${ }^{10} \mathrm{Be}$ records. This makes quantitative ${ }^{10}$ Be-based solar-activity reconstructions somewhat uncertain at present (see Figure 4d). For example, the differences between the Greenland and Antarctic ${ }^{10} \mathrm{Be}$ stack during the past 50 years (i.e. the normalization period) have an influence on the complete record when focusing on the comparison of recent to past solar activity. More specifically, this can lead to the conclusion of exceptional high solar activity in recent decades (Usoskin et al., 2003) compared to high, but not exceptional, solar activity during this period (Bard et al., 2000; Muscheler et al., 2007). The unphysical negative solar modulation inferred from the Greenland stack illustrates that this record very likely shows changes that are too strong to be explained by solar modulation alone. Using the production-rate calculations of Kovaltsov and Usoskin (2010) leads to less (but still) negative inferred solar modulation. In combination with the hypothesis of a so-called polar amplification (i.e. polar ${ }^{10} \mathrm{Be}$ records rather reflecting the polar production and not a global production signal (Mazaud, Laj, and Bender, 1994)), it might be argued that the Greenland ${ }^{10} \mathrm{Be}$ record is within the expected range of variability due to solar modulation. However, several arguments indicate problems in this reasoning: The real ${ }^{10} \mathrm{Be}$ range is even larger since we discuss a smoothed record (ten-year averages), i.e. eliminating the variability that is due to the 11-year cycle (Beer et al., 1990). In addition, there is no indication of a systematic polar bias in Greenland ${ }^{10} \mathrm{Be}$ records (Adolphi and Muscheler, 2016). Furthermore, the direct comparison of neutron monitor and ${ }^{10} \mathrm{Be}$ data illustrates the non-production influences in the Greenland ${ }^{10} \mathrm{Be}$ records during the past 60 years (e.g. Pedro et al., 2012).

Focusing on ${ }^{14} \mathrm{C}$ instead, Figure 9 shows the influence of different geomagnetic-field estimates and the differences arising from applying different production rate models. As mentioned, all curves are based on the same LIS spectrum (Potgieter et al., 2014). There is only a very small difference between the results using the two recent geomagnetic-field records (Licht et al., 2013; Nilsson et al., 2014). This is mainly due to the low sensitivity of cosmogenic-radionuclide production rate changes to variations in the geomagnetic field in periods of generally high geomagnetic-field intensities. The two resulting curves agree very well within the combined errors (blue and red lines in Figure 9). However, we note that potential systematic errors in the geomagnetic-field models could still be a significant source of uncertainty in the reconstructions. Figure 9 also illustrates that the differences in the production rate calculations have an influence on the absolute levels of solar modulation (mainly due to a normalization difference as shown in Figure 1). The absolute numbers for the solar-modulation function differ by about $10 \%$ for the results from the different production models. However, without the normalization difference, the ${ }^{14} \mathrm{C}$-based solar-modulation records are only slightly different. 


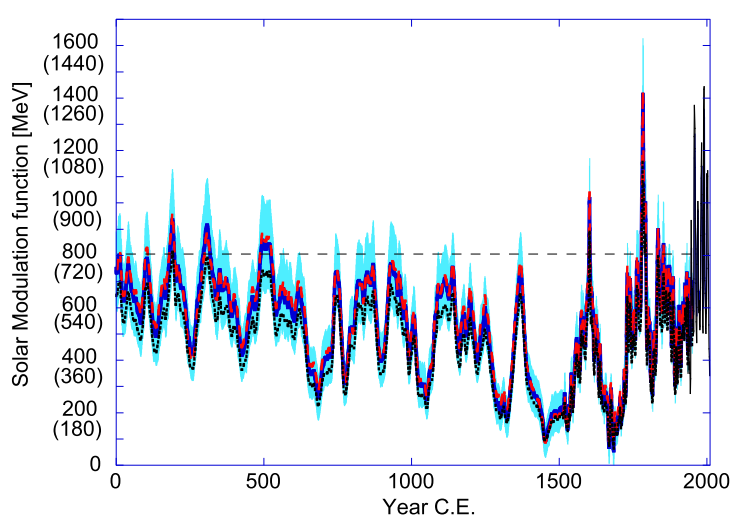

Figure 9 Comparison of the different ${ }^{14} \mathrm{C}$-based solar-modulation records. The dark-blue line with light-blue error band shows the results based on the production-rate calculations from Masarik and Beer (1999) and the pfm9k.1b geomagnetic-field model (Nilsson et al., 2014) connected to the neutron-monitor based solar modulation from McCracken and Beer (2007). The dashed-red curve shows the same calculation but using the AFM geomagnetic-field model (Licht et al., 2013). It largely overlaps with the blue line. The dotted-black curve shows the results using the production-rate calculations from Kovaltsov, Mishev, and Usoskin (2012) connected to the neutron-monitor-based solar modulation from Usoskin, Bazilevskaya, and Kovaltsov (2011) and the pfm9k.1b geomagnetic field model. Note that for this record the $y$-axis labels are indicated in the brackets, i.e. largely correcting for the $10 \%$ offset in neutron-monitor-based solar-modulation reconstruction shown in Figure 1. The horizontal-dashed line indicates the average neutron-monitor based solar-modulation function for the second part of the twentieth century.

\subsection{Comparison to the Revised Sunspot Record}

In the following we compare the Greenland, Antarctic, and ${ }^{14} \mathrm{C}$-based solar-modulation records to the revised sunspot records (Clette et al., 2014; Svalgaard and Schatten, 2016). As sunspot and radionuclide records react to different expressions of solar variability (magnetic fields on the Sun and the open magnetic flux), it is not a priori obvious that there should be a perfect correlation between these records. Nevertheless, there have been efforts to convert one into the other (Usoskin et al., 2003), and these reconstructed sunspot records correlate linearly to the radionuclide-based solar-modulation records from which they were derived. Therefore, we limit our comparison in the following to a direct linear comparison between solar modulation and revised sunspot records. Figure 10 shows the comparison between these records on timescales longer than 11 years. This comparison indicates a very close linear correlation between the two completely independent records of radionuclide-based solar modulation and sunspot numbers. Especially the record based on the production computations of Masarik and Beer (1999) $\left(\mathrm{C} 14_{\mathrm{MB}}\right)$ shows very close agreement with the sunspot record. Around 1750 C.E., the ${ }^{14} \mathrm{C}$-based record agrees better with the sunspot record (Clette et al., 2014), while the group sunspot numbers are systematically higher (Svalgaard and Schatten, 2016). Around 1950 C.E., there is some additional shortterm disagreement that might indicate an underestimation of the solar modulation based on the extended neutron-monitor record before 1950 C.E. and a possible underestimation of the solar modulation based on ${ }^{14} \mathrm{C}$ around this period (i.e. offsetting biases in the ${ }^{14} \mathrm{C}$ production rate and the extended neutron-monitor data). Comparing the sunspot records to the ${ }^{14} \mathrm{C}$-based results using the normalization based on Usoskin, Bazilevskaya, and Kovaltsov

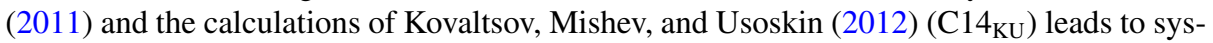
tematically lower solar-modulation values. We therefore scaled the $y$-axis differently (numbers in brackets in Figure 10) to minimize this systematic offset. This record also supports 


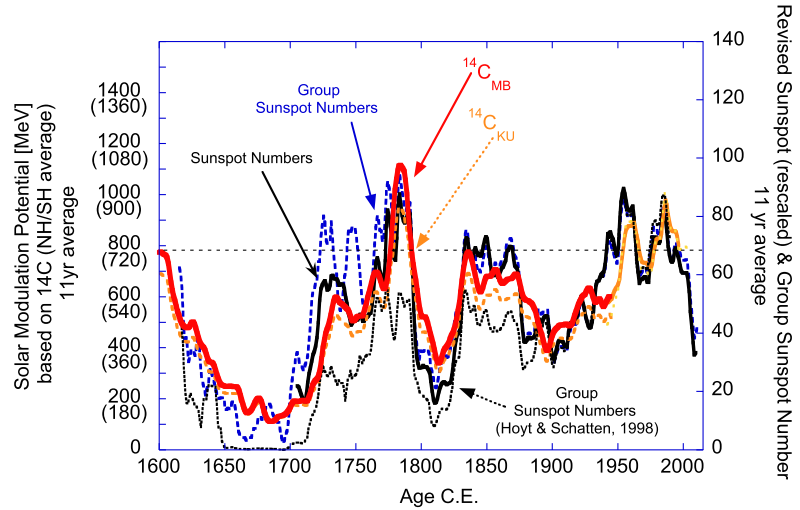

Figure 10 Comparison of the ${ }^{14} \mathrm{C}$ based solar-modulation function with the revised sunspot (black) and group sunspot (dashed-dark blue) numbers. All records show the running 11-year average. The red (orange) curve shows the ${ }^{14} \mathrm{C}$ (neutron monitor)-based results using the production calculations of Masarik and Beer (1999) (labeled C14 ${ }_{\mathrm{MB}}$ ). The dashed-orange curves show the results based on Kovaltsov, Mishev, and Usoskin (2012) normalized to the neutron-monitor-based reconstruction of Usoskin, Bazilevskaya, and Kovaltsov (2011) (labeled C14 $\mathrm{KU}$ ). Note the two different left $y$-axes, where the numbers for the solar-modulation potential in brackets refer to $\mathrm{C} 14_{\mathrm{KU}}$. It indicates that the relative changes in solar modulation are similar, but the different production rate models lead to about $10 \%$ different values in the absolute number of the solar-modulation potential. Similarly, the sunspot data have been rescaled $(-34 \%)$ to allow for a direct comparison to the Group Sunspot Number data. The old group sunspot record from Hoyt and Schatten (1998) is shown as the black dotted curve.

the high solar-activity values around 1780 on a level comparable to the second part of the twentieth century. For reference we also plot the outdated group sunspot record published by Hoyt and Schatten (1998). It is apparent that this record suggests significantly lower solar-activity levels before about 1900 C.E. compared to the revised sunspot records and the ${ }^{14} \mathrm{C}$-based solar-activity reconstruction.

Figure 11 shows the comparison of the different ${ }^{10} \mathrm{Be}$-based solar-modulation records with the sunspot records (same scaling as in Figure 10). The Antarctic ${ }^{10} \mathrm{Be}$-based record and the sunspot records agree well. The normalization procedure in combination with the large ${ }^{10} \mathrm{Be}$ trend in the Greenland record over the past 100 years leads to a generally much lower solar modulation based on this record. To use these ${ }^{10} \mathrm{Be}$-based records to test the revised sunspot record appears problematic since these records do not show a prefect agreement with the instrumental neutron-monitor data (see the black line in comparison to the ${ }^{10}$ Be-based solar modulation in Figure 11). Therefore, apparent climate or weather influences in the records are already visible in the ${ }^{10} \mathrm{Be}$ record for the normalization period. The aforementioned differences between Greenland and Antarctic ${ }^{10} \mathrm{Be}$ data indicate that such influences are also present further back in time. We currently do not have adequate models to independently correct for such influences in the ${ }^{10} \mathrm{Be}$ record.

\subsection{The 11-Year Cycle in the ${ }^{14} \mathrm{C}$ Data}

The revised group-sunspot record exhibits more counts during the Maunder minimum from about 1650 to 1700 C.E. compared to the previously published group sunspot record. In the following we investigate whether the ${ }^{14} \mathrm{C}$ record can be used to test this short-term variability during the last, and only directly observed, grand solar minimum. The upper panel of Figure 12 shows the revised group-sunspot record in comparison with the ${ }^{14} \mathrm{C}$-based solar 


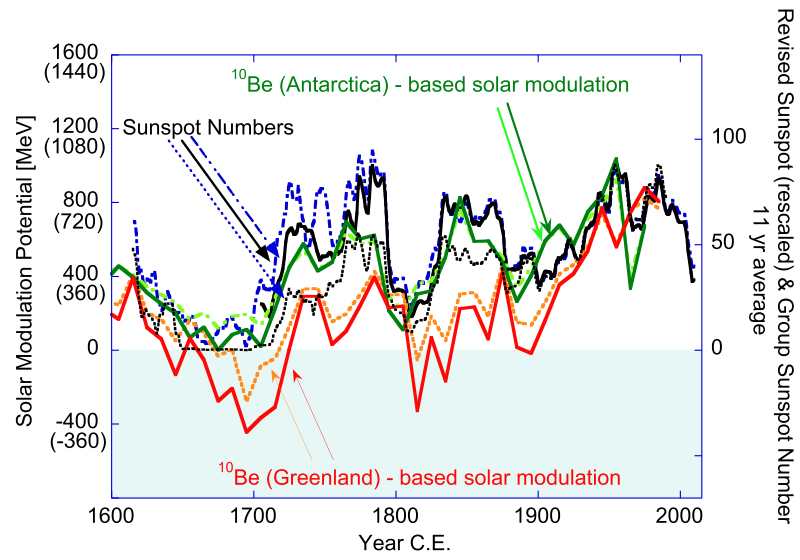

Figure 11 Comparison of revised sunspot records (black and dashed-blue curves) to ${ }^{10} \mathrm{Be}-$ based solar modulation records. The sunspot data show running 11 -year averages and the ${ }^{10} \mathrm{Be}$ data is based on the ten-year averages shown in previous figures. The ${ }^{10} \mathrm{Be}$-based records are normalized to obtain agreement between neutron monitor and ${ }^{10} \mathrm{Be}$-based solar modulation in the period of overlap. The dark- and light-green curves show the solar modulation based on the Antarctic ${ }^{10} \mathrm{Be}$ data using the production-rate calculations of Masarik and Beer (1999) and Kovaltsov and Usoskin (2010), respectively. The red and orange curves show the solar modulation based on the Greenland ${ }^{10} \mathrm{Be}$ data using the production rate calculations of Masarik and Beer (1999) and Kovaltsov and Usoskin (2010), respectively. The unphysical range (negative solar modulation) is indicated by the shading. The scaling between sunspots and solar modulation is the same as in Figure 10 and the numbers for the solar-modulation potential in brackets refer to the calculations based on Kovaltsov and Usoskin (2010). The old group sunspot record from Hoyt and Schatten (1998) is shown as the dotted-black curve.

Figure 12 Upper panel: comparison of unfiltered ${ }^{14} \mathrm{C}$-based solar modulation $\left(\mathrm{C} 14_{\mathrm{MB}}\right.$, dotted red) with the revised group sunspot number (upper panel, blue). Lower panel: comparison of detrended and bandpass filtered

( $1 / 20$ years $-1 / 5$ years) records. The dotted-orange line in the upper panel shows the solar modulation inferred from the extended neutron-monitor data (filtered record not shown).

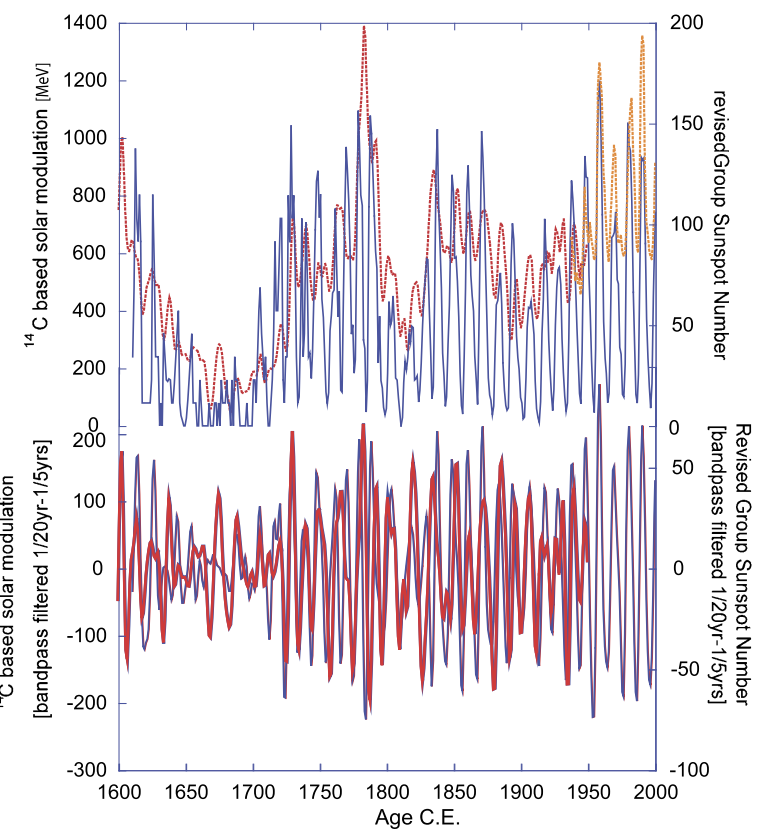


modulation record calculated in this study. The lower panel shows the comparison of the two time series for variability only on timescales from 5 to 20 years (FFT band-pass filter). Considering the smoothing of the atmospheric ${ }^{14} \mathrm{C}$ variations connected to short-term changes, it is notable that most of the 11-year variability is reflected in the ${ }^{14} \mathrm{C}$-based record and that the timing of the changes is mostly synchronous with the sunspot record. In particular, focusing on the Maunder minimum shows a reasonable agreement. As has been observed in ${ }^{10} \mathrm{Be}$ data (Beer et al., 1990), the ${ }^{14} \mathrm{C}$ record shows continued solar modulation during the Maunder minimum. An exact comparison of the 11 -year cycle variability in ${ }^{14} \mathrm{C}$ and group sunspots is challenged by the relatively small amplitude of the 11-year cycle during the Maunder minimum, which decreases the signal-to-noise ratio in both records. Occasional periods of disagreement could hence indicate uncertainties in either record. Nevertheless, the ${ }^{14} \mathrm{C}$ record lends some support to the short-term variability in the group sunspot record during the Maunder minimum.

\section{Conclusions}

We presented an update of ${ }^{10} \mathrm{Be}$ and ${ }^{14} \mathrm{C}$-based solar modulation reconstructions for the past 2000 years and a comparison to the revised sunspot records. We note that the difference in Greenland and Antarctic ${ }^{10} \mathrm{Be}$ data can lead to disagreeing conclusions about past solaractivity levels. This difference is most likely due to weather and climate influences on the records. ${ }^{14} \mathrm{C}$ is less strongly affected by such influences, but the ${ }^{14} \mathrm{C}$-based solar modulation includes some additional uncertainty owing to the necessity to connect the data to the more uncertain pre-1950 extended neutron-monitor data. The ${ }^{14} \mathrm{C}$ and the Antarctic ${ }^{10} \mathrm{Be}$ data both lead to similar solar-activity reconstructions, while the Greenland ${ }^{10} \mathrm{Be}$ records show changes in recent centuries that are too large to be explained by solar modulation alone. In general, the sunspot and radionuclide records agree well. Especially the ${ }^{14} \mathrm{C}$-based record agrees very well with the revised sunspot data, lending strong support to these revisions.

Acknowledgements We thank the anonymous referee for their constructive comments. This article was inspired by a PAGES Solar Forcing Working Group workshop in Davos in 2014. This work was supported by the Swedish Research Council (grant DNR2013-8421 to R. Muscheler).

Disclosure of Potential Conflicts of Interest The authors declare that they have no conflicts of interest.

Open Access This article is distributed under the terms of the Creative Commons Attribution 4.0 International License (http://creativecommons.org/licenses/by/4.0/), which permits unrestricted use, distribution, and reproduction in any medium, provided you give appropriate credit to the original author(s) and the source, provide a link to the Creative Commons license, and indicate if changes were made.

\section{References}

Adolphi, F., Muscheler, R.: 2016, Synchronizing the Greenland ice core and radiocarbon timescales over the Holocene - Bayesian wiggle-matching of cosmogenic radionuclide records. Clim. Past 12, 15.

Adolphi, F., Muscheler, R., Svensson, A., Aldahan, A., Possnert, G., Beer, J., Sjolte, J., Bjorck, S., Matthes, K., Thieblemont, R.: 2014, Persistent link between solar activity and Greenland climate during the Last Glacial Maximum. Nat. Geosci. 7, 662.

Bard, E., Raisbeck, G.M., Yiou, F., Jouzel, J.: 2000, Solar irradiance during the last 1200 years based on cosmogenic nuclides. Tellus 52B, 985.

Baroni, M., Bard, E., Petit, J.-R., Magand, O., Bourlès, D.: 2011, Volcanic and solar activity, and atmospheric circulation influences on cosmogenic ${ }^{10} \mathrm{Be}$ fallout at Vostok and Concordia (Antarctica) over the last 60 years. Geochim. Cosmochim. Acta 75, 7132. 
Beer, J., Raisbeck, G.M., Yiou, F.: 1991, Time variations of ${ }^{10}$ Be and solar activity. In: Sonett, C.P., Giampapa, M.S., Matthews, M.S. (eds.) The Sun in Time, University of Arizona Press, Tucson, 343.

Beer, J., Siegenthaler, U., Bonani, G., Finkel, R.C., Oeschger, H., Suter, M., Wölfli, W.: 1988, Information on past solar activity and geomagnetism from ${ }^{10} \mathrm{Be}$ in the Camp Century ice core. Nature 331, 675.

Beer, J., Blinov, A., Bonani, G., Finkel, R.C., Hofmann, H.J., Lehmann, B., Oeschger, H., Sigg, A., Schwander, J., Staffelbach, T., Stauffer, B., Suter, M., Wölfli, W.: 1990 , Use of ${ }^{10}$ Be in polar ice to trace the 11-year cycle of solar activity. Nature 347, 164.

Berggren, A.-M., Beer, J., Possnert, G., Aldahan, A., Kubik, P., Christl, M., Johnsen, S.J., Abreu, J., Vinther, B.M.: 2009, A 600 -year annual ${ }^{10}$ Be record from the NGRIP ice core, Greenland. Geophys. Res. Lett. 36, L11801. DOI.

Bond, G., Kromer, B., Beer, J., Muscheler, R., Evans, M.N., Showers, W., Hoffmann, S., Lotti-Bond, R., Hajdas, I., Bonani, G.: 2001, Persistent solar influence on North Atlantic climate during the Holocene. Science 294, 2130.

Burger, R.A., Potgier, M.S., Heber, B.: 2000, Rigidity dependence of cosmic ray proton latitudinal gradients measured by the Ulysses spacecraft: Implications for the diffusion tensor. J. Geophys. Res. 105, 27447.

Caffee, M.W., Nishiizumi, K., Sisterson, J.M., Ullmann, J., Welten, K.C.: 2013, Cross section measurements at neutron energies 71 and $112 \mathrm{MeV}$ and energy integrated cross section measurements $\left(0.1<E_{n}<\right.$ $750 \mathrm{MeV})$ for the neutron induced reactions $\mathrm{O}(n, x){ }^{10} \mathrm{Be}, \mathrm{Si}(n, x){ }^{10} \mathrm{Be}$, and $\mathrm{Si}(n, x)^{26} \mathrm{Al}$. Nucl. Instrum. Methods Phys. Res., Sect. B, Beam Interact. Mater. Atoms 294, 479.

Clette, F., Svalgaard, L., Vaquero, J., Cliver, E.: 2014, Revisiting the sunspot number. Space Sci. Rev. 186, 35.

Damon, P.E., Sonett, C.P.: 1991, Solar and terrestrial components of the atmospheric C-14 variation spectrum. In: Sonett, C.P., Giampapa, M.S., Matthews, M.S. (eds.) The Sun in Time, University of Arizona Press, Tucson, 360.

Field, C.V., Schmidt, G.A., Koch, D., Salyk, C.: 2006, Modeling production and climate-related impacts on ${ }^{10}$ Be concentration in ice cores. J. Geophys. Res. 111, D15107. DOI.

Garcia-Munoz, M., Mason, G.M., Simpson, J.A.: 1975, The anomalous 4He component in the cosmic-ray spectrum at $60 \mathrm{MeV}$ per nucleon during 1973 - 1974. Astrophys. J. 202, 265. DOI.

Gleeson, L.J., Axford, W.I.: 1968, Solar modulation of galactic cosmic rays. Astrophys. J. 154, 1011.

Heikkilä, U., Beer, J., Abreu, J.A., Steinhilber, F.: 2011, On the atmospheric transport and deposition of the cosmogenic radionuclides $\left({ }^{10} \mathrm{Be}\right)$ : A review. Space Sci. Rev. 176, 321.

Herbst, K.: 2013, Interaction of cosmic rays with the Earth's magnetosphere and atmosphere. Ph.D. thesis, University of Kiel, Germany.

Herbst, K., Kopp, A., Heber, B., Steinhilber, F., Fichtner, H., Scherer, K., Matthiä, D.: 2010, On the importance of the local interstellar spectrum for the solar modulation parameter. J. Geophys. Res. 115. DOI.

Hogg, A.G., Hua, Q., Blackwell, P.G., Buck, C.E., Guilderson, T.P., Heaton, T.J., Niu, M., Palmer, J.G., Reimer, P.J., Reimer, R.W., Turney, C.S.M., Zimmerman, S.R.H.: 2013, SHCal13 southern hemisphere calibration, 0-50,000 years cal BP. Radiocarbon 55. DOI.

Horiuchi, K., Uchida, T., Sakamoto, Y., Ohta, A., Matsuzaki, H., Shibata, Y., Motoyama, H.: 2008, Ice core record of ${ }^{10} \mathrm{Be}$ over the past millennium from Dome Fuji, Antarctica: A new proxy record of past solar activity and a powerful tool for stratigraphic dating. Quat. Geochron. 3, 253.

Hoyt, D.V., Schatten, K.H.: 1998, Group sunspot numbers: A new solar activity reconstruction. Solar Phys. 179, 189. DOI.

Jackson, A., Jonkers, A.R.T., Walker, M.R.: 2000, Four centuries of geomagnetic secular variation from historical records. Phil. Trans. Roy. Soc. London A 358, 957.

Knudsen, M.F., Riisager, P., Donadini, F., Snowball, I., Muscheler, R., Korhonen, K., Pesonen, L.J.: 2008, Variations in the geomagnetic dipole moment during the Holocene and the past 50 kyr. Earth Planet. Sci. Lett. 272, 319.

Korte, M., Constable, C.: 2005, The geomagnetic dipole moment over the last 7000 years - New results from a global model. Earth Planet. Sci. Lett. 236, 348.

Korte, M., Muscheler, R.: 2012, Centennial to millennial geomagnetic field variations. J. Space Weather Space Clim. 2. DOI.

Kovaltsov, G.A., Mishev, A., Usoskin, I.G.: 2012, A new model of cosmogenic production of radiocarbon 14C in the atmosphere. Earth Planet. Sci. Lett. 337-338, 114.

Kovaltsov, G.A., Usoskin, I.G.: 2010, A new 3D numerical model of cosmogenic nuclide ${ }^{10}$ Be production in the atmosphere. Earth Planet. Sci. Lett. 291, 182.

Lal, D., Peters, B.: 1967, Cosmic ray produced radioactivity on the Earth. In: Flügge, S. (ed.) Handbuch der Physik 46/2, Springer, Berlin, 551. 
Licht, A., Hulot, G., Gallet, Y., Thébault, E.: 2013, Ensembles of low degree archeomagnetic field models for the past three millennia. Phys. Earth Planet. Inter. 224, 38.

Masarik, J., Beer, J.: 1999, Simulation of particle fluxes and cosmogenic nuclide production in the Earth's atmosphere. J. Geophys. Res. 104, 12099.

Mazaud, A., Laj, C., Bender, M.: 1994, A geomagnetic chronology for Antarctic ice accumulation. Geophys. Res. Lett. 21, 337.

McCracken, K.G., Beer, J.: 2007, Long-term changes in the cosmic ray intensity at Earth, 1428-2005. J. Geophys. Res. 112. DOI.

Moraal, H.: 2013, Cosmic-ray modulation equations. Space Sci. Rev. 176, 299.

Muscheler, R., Beer, J., Wagner, G., Laj, C., Kissel, C., Raisbeck, G.M., Yiou, F., Kubik, P.W.: 2004, Changes in the carbon cycle during the last deglaciation as indicated by the comparison of ${ }^{10} \mathrm{Be}$ and ${ }^{14} \mathrm{C}$ records. Earth Planet. Sci. Lett. 219, 325.

Muscheler, R., Joos, F., Beer, J., Mueller, S.A., Vonmoos, M., Snowball, I.: 2007, Solar activity during the last $1000 \mathrm{yr}$ inferred from radionuclide records. Quat. Sci. Rev. 26, 82. DOI.

Nilsson, A., Muscheler, R., Snowball, I.: 2011, Millennial scale cyclicity in the geodynamo inferred from a dipole tilt reconstruction. Earth Planet. Sci. Lett. 311, 299.

Nilsson, A., Holme, R., Korte, M., Suttie, N., Hill, M.: 2014, Reconstructing Holocene geomagnetic field variation: New methods, models and implications. Geophys. J. Int. DOI.

Nishiizumi, K., Finkel, R.C.: 2007, Cosmogenic radionuclides in the siple dome A ice core, Version 1, National Snow and Ice Data Center. DOI.

Panovska, S., Korte, M., Finlay, C.C., Constable, C.G.: 2015, Limitations in paleomagnetic data and modelling techniques and their impact on Holocene geomagnetic field models. Geophys. J. Int. 202, 402.

Parker, E.N.: 1965, The passage of energetic charged particles through interplanetary space. Planet. Space Sci. 13, 9 .

Pedro, J.B., van Ommen, T., Curran, M., Morgan, V., Smith, A., McMorrow, A.: 2006, Evidence for climate modulation of the ${ }^{10} \mathrm{Be}$ solar activity proxy. J. Geophys. Res. 111, D21105.

Pedro, J.B., Heikkilä, U.E., Klekociuk, A., Smith, A.M., van Ommen, T.D., Curran, M.A.J.: 2011, Beryllium10 transport to Antarctica: Results from seasonally resolved observations and modeling. J. Geophys. Res. 116. DOI.

Pedro, J.B., McConnell, J.R., van Ommen, T.D., Fink, D., Curran, M.A.J., Smith, A.M., Simon, K.J., Moy, C.M., Das, S.B.: 2012, Solar and climate influences on ice core ${ }^{10}$ Be records from Antarctica and Greenland during the neutron monitor era. Earth Planet. Sci. Lett. 355-356, 174.

Potgieter, M.S., Vos, E.E., Boezio, M., De Simone, N., Di Felice, V., Formato, V.: 2014, Modulation of galactic protons in the heliosphere during the unusual solar minimum of 2006 to 2009. Solar Phys. 289, 391. DOI.

Raisbeck, G.M., Yiou, F.: 2004, Comment on "Millennium Scale Sunspot Number Reconstruction: Evidence for an Unusually Active Sun Since the 1940s". Phys. Rev. Lett. 92. DOI.

Raisbeck, G.M., Yiou, F., Fruneau, M., Loiseaux, J.M., Lieuvin, M., Ravel, J.C., Lorius, C.: 1981, Cosmogenic ${ }^{10}$ Be concentrations in Antarctic ice during the past 30,000 years. Nature 292, 825 .

Raisbeck, G.M., Yiou, F., Jouzel, J., Petit, J.R.: $1990,{ }^{10} \mathrm{Be}$ and $\partial^{2} \mathrm{H}$ in polar ice cores as a probe of the solar variability's influence on climate. Phil. Trans. Roy. Soc. London A 330, 65.

Reimer, P., Bard, E., Bayliss, A., Beck, J.W., Blackwell, P.G., Bronk Ramsey, C., Buck, C.E., Cheng, H., Edwards, R.L., Friedrich, M., Grootes, P., Guilderson, T.P., Haflidison, H., Hajdas, I., Hatté, C., Heaton, T.J., Hoffmann, D.L., Hogg, A.G., Hughen, K.A., Kaiser, K.F., Kromer, B., Manning, S.W., Niu, M., Reimer, R.W., Richards, D.A., Scott, E.M., Southon, J., Staff, R.A., Turney, C.S.M., van der Plicht, J.: 2013, IntCal13 and Marine13 radiocarbon age calibration curves 0-50,000 years cal BP. Radiocarbon 55, 1869.

Roberts, A.P., Winklhofer, M.: 2004, Why are geomagnetic excursions not always recorded in sediments? Constraints from post-depositional remanent magnetization lock-in modelling. Earth Planet. Sci. Lett. 227, 345 .

Roth, R., Joos, F.: 2013, A reconstruction of radiocarbon production and total solar irradiance from the Holocene 14C and CO2 records: Implications of data and model uncertainties. Clim. Past 9, 1879.

Schmidt, G.A., Jungclaus, J.H., Ammann, C.M., Bard, E., Braconnot, P., Crowley, T.J., Delaygue, G., Joos, F., Krivova, N.A., Muscheler, R., Otto-Bliesner, B.L., Pongratz, J., Shindell, D.T., Solanki, S.K., Steinhilber, F., Vieira, L.E.A.: 2012, Climate forcing reconstructions for use in PMIP simulations of the last millennium (v1.1). Geosci. Model Dev. 5, 185. DOI.

Simpson, J.A.: 2000, The cosmic ray nucleonic component: The invention and scientific uses of the neutron monitor. Space Sci. Rev. 93, 11.

Snowball, I., Muscheler, R.: 2007, Palaeomagnetic intensity data: An Achilles heel of solar activity reconstructions. Holocene 17, 851 
Solanki, S.K., Usoskin, I.G., Kromer, B., Schüssler, M., Beer, J.: 2004, Unusual activity of the Sun during recent decades compared to the previous 11,000 years. Nature 431, 1084. DOI.

Steinhilber, F., Abreu, J.A., Beer, J., Brunner, I., Christl, M., Fischer, H., Heikkilä, U., Kubik, P.W., Mann, M., McCracken, K.G., Miller, H., Miyahara, H., Oerter, H., Wilhelms, F.: 2012, 9,400 years of cosmic radiation and solar activity from ice cores and tree rings. Proc. Natl. Acad. Sci. USA 109, 5967. DOI.

Stone, E.C., Cummings, A.C., McDonald, F.B., Heikkila, B.C., Lal, N., Webber, W.R.: 2013, Voyager 1 observes low-energy galactic cosmic rays in a region depleted of heliospheric ions. Science 341, 150.

Stuiver, M., Reimer, P.J., Braziunas, T.F.: 1998, High-precision radiocarbon age calibration for terrestrial and marine samples. Radiocarbon 40, 1127.

Svalgaard, L., Schatten, K.H.: 2016, Reconstruction of the sunspot group number: The Backbone method. Solar Phys. 291. DOI.

Thebault, E., Finlay, C., Beggan, C., Alken, P., Aubert, J., Barrois, O., Bertrand, F., Bondar, T., Boness, A., Brocco, L., Canet, E., Chambodut, A., Chulliat, A., Coisson, P., Civet, F., Du, A., Fournier, A., Fratter, I., Gillet, N., Hamilton, B., Hamoudi, M., Hulot, G., Jager, T., Korte, M., Kuang, W., Lalanne, X., Langlais, B., Leger, J.-M., Lesur, V., Lowes, F.: 2015, Evaluation of candidate geomagnetic field models for IGRF-12. Earth Planets Space 67, 112. DOI.

Usoskin, I.G., Bazilevskaya, G.A., Kovaltsov, G.A.: 2011, Solar modulation parameter for cosmic rays since 1936 reconstructed from ground-based neutron monitors and ionization chambers. J. Geophys. Res. 116. DOI.

Usoskin, I.G., Solanki, S.K., Schüssler, M., Mursula, K., Alanko, K.: 2003, A millennium scale sunspot number reconstruction: Evidence for an unusually active sun since the 1940's. Phys. Rev. Lett. 91, 211101.

Usoskin, I.G., Alanko-Huotari, K., Kovaltsov, G.A., Mursula, K.: 2005, Heliospheric modulation of cosmic rays: Monthly reconstruction for $1951-2004$. J. Geophys. Res. 110, A12108. DOI.

Wagner, G., Masarik, J., Beer, J., Baumgartner, S., Imboden, D., Kubik, P.W., Synal, H.-A., Suter, M.: 2000, Reconstruction of the geomagnetic field between $2060 \mathrm{kyr}$ BP from cosmogenic radionuclides in the GRIP ice core. Nucl. Instrum. Methods Phys. Res., Sect. B, Beam Interact. Mater. Atoms 172, 597.

Webber, W.R., Higbie, P.R.: 2010, What Voyager cosmic ray data in the outer heliosphere tells us about ${ }^{10} \mathrm{Be}$ production in the Earth's polar atmosphere in the recent past. J. Geophys. Res. 115, A05102. DOI.

Yiou, F., Raisbeck, G.M., Baumgartner, S., Beer, J., Hammer, C., Johnsen, S., Jouzel, J., Kubik, P.W., Lestringuez, J., Stiévenard, M., Suter, M., Yiou, P.: 1997, Beryllium 10 in the Greenland ice core project ice core at summit, Greenland. J. Geophys. Res. 102, 26783. 